\title{
Medical Humanities: An E-Module at the University of Manchester
}

\author{
SIMONA GIORDANO
}

The importance of humanities in the medical curriculum is increasingly recognized. For example, in the United Kingdom, The General Medical Council (GMC), which is an independent body established under the Medical Act 1858 and responsible, among other things, for fostering good medical practice and promoting high standards of medical education, in its publication Tomorrow's Doctors, ${ }^{1}$ encouraged inclusion of humanities in the medical curriculum. Literature, arts, poetry, and philosophy are thought to foster the doctors' ability to "communicate with patients, to penetrate more deeply into the patient's wider narrative, and to seek more diverse ways of promoting well being and reducing the impact of illness or disability. ${ }^{2}$ The Institute of Medical Ethics, ${ }^{3}$ as well as several other organizations including the American Society for Bioethics and Humanities, ${ }^{4}$ has also fostered the incorporation of literature and arts in the undergraduate medical curriculum.

In response to the calls for broader humanistic input, the Medical School in Manchester accepted a proposal to include a Medical Humanities Module (MHM) in the undergraduate medical curriculum.

In this paper, I explain the aims and content of the MHM. I thus wish to share an innovative teaching tool with any interested medical ethics educator. I hope to inspire other medical ethics teachers to draw on sources other than jurisprudence and applied ethics for the teaching of medical ethics and law, even at an undergraduate level. I also wish to offer some practical ideas of themes and teaching material that could be incorporated into an ethics and law curriculum.

It is important to note that this MHM is an e-learning module. This means that all lectures, reading material, questions for discussion and interactive learning happen in the virtual learning environment (VLE). I will show how e-learning can help medical educators to meet some of the challenges in medical education and will discuss the pros and cons of this relatively novel method of delivery.

\section{Course Aims and Content}

The main aims of this MHM are

- To enhance students' abilities to engage with different types of discourses around medicine

I thank Dr. Caroline Boggies for the support given to this enterprise. My gratitude to Professor Margaret Brazier for having read and commented on this paper. A special thanks to the 30 students who have volunteered to take this course and who have contributed to make it so interesting for me. 
- To refine the students' sensitivity to ethical, pastoral, and communication issues as "human" matters 5

- To help students to view medicine not just as clinical practice, but as a science "of the human"

- To explain ethico-legal issues with a different language, the language of the arts

- To give students new interests and food for thought and to help them to discover areas of creativity that are relevant to medicine

- To produce not just excellent clinicians but humane professionals with a broad cultural outlook.

The common denominator of about two thirds of my MHM is the end of life. The choice was made for a number of reasons, mainly relating to the overall medical ethics curriculum that we run across the 5 years. Another major reason is that the end of life gives the possibility to explore many important ethico-legal themes, such as confidentiality and therapeutic privilege, informed consent, the role of empathy in clinical practice, communication skills, the right to remain ignorant, the right to play God, and ethical issues in clinical research. In the Manchester Medical School, these have already been delivered in previous years, and the MHM gives the possibility to reanalyze these themes from a different angle. Humanities, however, can be incorporated in a variety of ways, and there is no need to focus on one main theme. There is an abundance of literature and filmography on genetics, genetic engineering, cloning, doctor-patient relationship, research ethics, mental health, treating children, and so on. Potentially, any of the 12 topics that form the core curriculum ${ }^{6}$ can be covered in a MHM.

\section{Course Description}

The MHM that I have designed includes three sessions, which run across a period of 8 weeks. Each session comprises an e-lecture, a self-directed learning phase, and a discussion board. The first session is "Medicine, Cinema and Philosophy," the second is "Medicine and Literature," and the third is "Medicine and Theater." The module also includes references to real cases.

Students are encouraged to log in on the discussion board at the end of each session, answer the questions, and share their thoughts, experiences (anonymized), and any ideas, films, books or other materials that they might think are relevant to the module.

\section{Example of a Session: Session 1}

E-lecture. In the opening lecture I show the students a number of pictures and ask them what all these items have in common. The pictures are Masaccio's painting L'espulsione dal Paradiso, ${ }^{7}$ where Adam and Eve are expelled from Heaven. Adam covers his face in despair and Eve attempts to veil herself with her hands, ashamed of her nudity. The second picture is the photo of a fragment of a ceramic made by Bernard Palissy. Palissy was a ceramist in the 1500s and is known today for his discoveries on metals and water channels. ${ }^{8}$ The third picture is a realistic replication of a thorax, presented at an exhibition on body in arts and medicine in Lyon in 2008. ${ }^{9}$ The fourth picture is a photo of La Pietà by Michelangelo. ${ }^{10}$ This 
sculpture is currently held in St. Peter's Chapel in Rome. Here a young Mary holds the dead body of Jesus. Like Masaccio's painting, La Pietà illustrates the artist's sound familiarity with human anatomy and physiology. The fifth picture is a tattoo, and the next is a photo of a painting by Gottlob Haubmann, which is thought to represent J. S. Bach. ${ }^{11}$ Then I show the reconstruction of the face of Bach by Caroline Wilkinson, an anthropologist. ${ }^{12}$ There is a story behind Caroline Wilkinson's work. It had never been clear that Haubmann's portrait was truly a representation of Bach. The remains of Bach were thus exhumed in 1894 by Wilhem Hiss, an anatomist, and Carl Seffnerr, an artist, in order to reconstruct his bust and his face. Wilkinson, thanks to a sophisticated method of facial reconstruction, virtually sculpted Bach's face. The next picture I show is the photo of The City of Arts and Sciences in Valencia, ${ }^{13}$ by Santiago Calatrava. Calatrava is one of the most famous contemporary architects. Calatrava often takes inspiration from the bodies of animals and humans. His museum in Valencia replicates a human eye; it mimics an eyelid, which opens up and closes on the sea. Finally, I show one of Leonardo da Vinci's drawings of the human body. ${ }^{14}$ Leonardo is known to have dissected several bodies and, thanks to his artistic genius, has given us very faithful representations of what he saw. These drawings today are placed at the intersection between medicine and arts: they have inestimable scientific value, and Leonardo is considered one of the fathers of modern medicine, and equally they are the priceless expression of Leonardo's unique artistic endowment.

I suggest that these are all examples of how medicine and the arts or, more generally, humanities, mingle with each other. Throughout the module, I explain the connection between each picture and medicine and show the students the more general links between medicine and various humanistic disciplines, such as sociology, law, philosophy, cinema, architecture, and literature (see Figure 1).

I offer one interpretation of medical humanities, and why they are relevant to clinical practice. I explore the meanings of the terms "medicine" and "humanities," and I attempt to show how science and the arts have historically been interrelated and how they are in some ways inseparable; I show how the arts have served science and vice versa, using the works of Leonardo da Vinci, Andrea Vasalio, and others to illustrate the point. I discuss the connection between medicine and various other disciplines. For example, I consider the impact of architecture on human health and also how medicine has sometimes inspired architectural works, and I use Calatrava's work as an illustration of this. Medicine is also a source of inspiration for the arts, as the exhibitions on the arts and medicine also highlight. Conversely, arts are used in medicine: dance therapy, drama therapy, and music therapies are examples of how arts are thought to have a healing effect. Richard Lipping, founder of the International Arts-Medicine Association (IAMA) writes: "The true healer neither knows nor seeks boundaries between the arts and medicine." ${ }^{15}$ In this first lecture, I also discuss the interrelation between medicine and law, philosophy, economics, sociology, cinema, poetry, and literature, always bringing examples of how medicine has inspired these other disciplines and how these impact directly or indirectly on clinical practice.

Self-Directed Learning (SDL). The students are asked to read On Suicide by David Hume. The text is uploaded on the VLE. The students' package includes explanatory notes, identification of ethical and legal issues, and questions for discussion. 


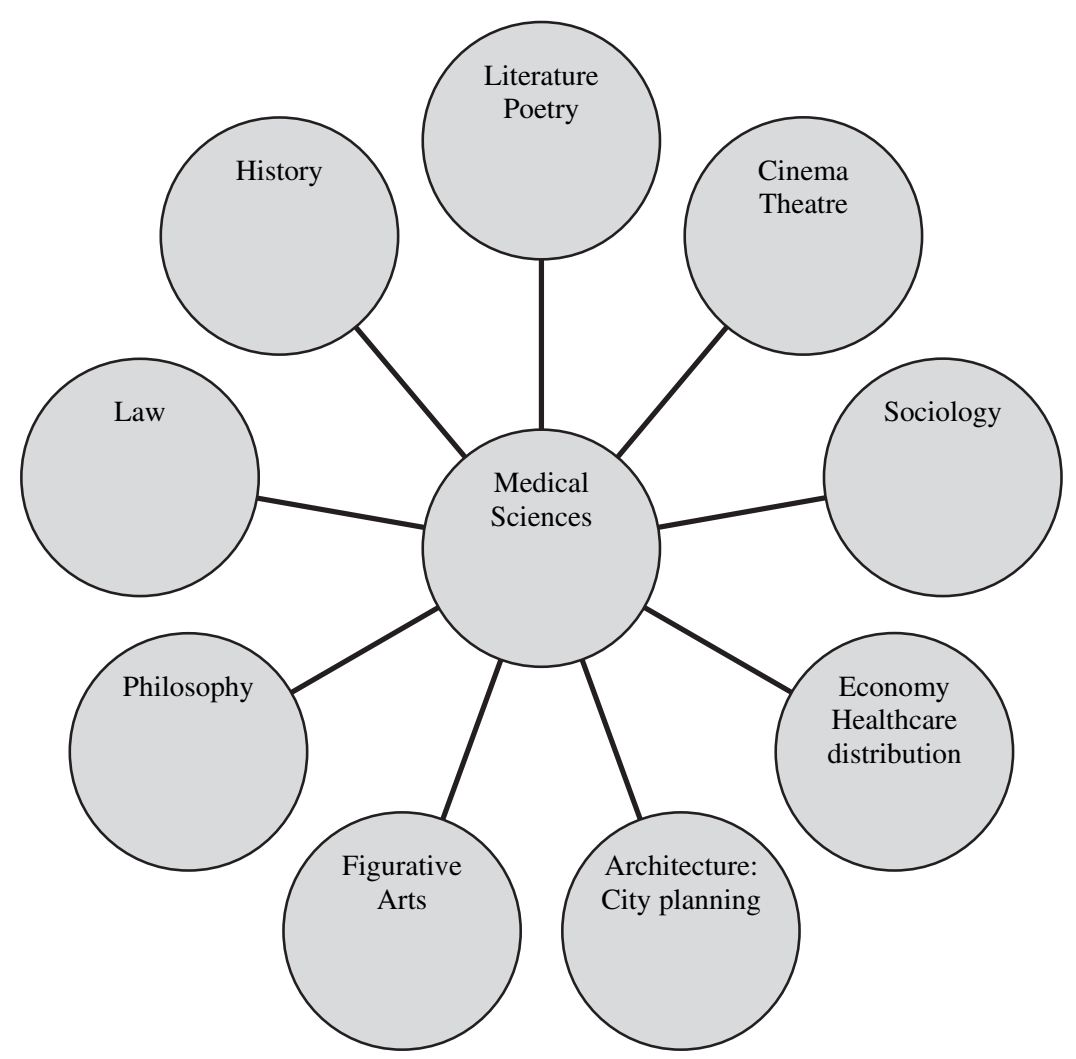

Figure 1. Disciplines discussed in E-lecture 1. The links between these and medicine are explored.

Film. The students are invited to watch The Barbarian Invasions. This film narrates the story of a man who suffers an untreatable form of cancer. His son decides to remove him from hospital care and invites his closest friends to share a house, to accompany him all together toward the end of his life. The daughter of one of his girlfriends is a heroin addict. She provides palliation during the course of his disease, in the form of illegal drugs. When he requests, she provides an overdose of heroin.

Real cases. The students are offered a real case, and the connections are drawn between the philosophy text, the film, and real-life issues. The case in this session is Eluana Englaro. ${ }^{16}$ Eluana was in a persistent vegetative state for 14 years. Prior to the incident that caused her to fall into a persistent vegetative state, she said to her father that, should this ever happen to her, she would have liked to have lifesupport therapies removed. Her father, however, was not allowed by the Italian Courts to withdraw consent to artificial nutrition and hydration on her behalf. After many years of legal battles, in 2009 life-support therapies were interrupted. Ethical issues relating to the validity of advance directives and to the value of life were identified and discussed in the online forum.

Discussion board. The discussion boards last a week. Table 1 contains some sample questions, and Table 2 reports some of the students' entries, both from 
Table 1. Sample Questions from Session $1^{\mathrm{a}}$

Questions on Session 1: Answer at least 3

Q1. Hume writes "nor are the human faculties less his workmanship, than the laws of motion and gravitation. ... There is no event, however important to us, which he [God] has exempted from the general laws that govern the universe." If there is no conceptual or substantial difference between human and natural, what are the implications of this for clinical practice?

Q2. Hume argues that the termination of one human life is of no interest to the universe. "The life of a man is of no greater importance to the universe than that of an oyster."

Question: What do you think about this? What are the implications of this for clinical practice, and, in particular, with regard to respect for people's wishes to refuse medical treatment/to terminate their life?

Q3. Hume talks of suicide as an act of bravery. Question: Do you agree? Is it cowardice, bravery? Or can there be no moral judgment attached to it?

Q4. Hume says that when I am a burden to society, it would be laudable if I wanted to put an end to my life. Baroness Warnock claimed that people with dementia have a "duty to die." ${ }^{\prime b}$ Do you think this is right?

Q5. What are the morally relevant differences between Eluana Englaro and the protagonist of The Barbarian Invasions?

Q6. Was it unethical to administer "home-made" euthanasia? Explain and justify your answer.

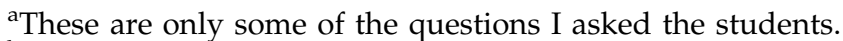

'Martin Beckford, Baroness Warnock. Dementia sufferers may have a "duty to die,"

Telegraph, 18 Sept 2008; available at http:/ /www.telegraph.co.uk/news/uknews/2983652/

Baroness-Warnock-Dementia-sufferers-may-have-a-duty-to-die.html? source $=$ EMC-new 19092008 (last accessed 26 May 2010).

Session 1. We had a total of 160 entries. The students overall engaged with one another in lively debates and showed great interest in the themes.

\section{Session 2: Brief Overview}

Session 2 is "Medicine and Literature." The students are required to read The Death of Ivan Ilych. An e-lecture explaining the relevant ethical and legal themes raised by the novel is uploaded in the VLE. The Death of Ivan Ilych is a novel by Leo Tolstoy. It is the story of a judge, Ivan Ilych, who suffers increasing pain in his abdomen. His wife and children seem aware that his condition is terminal, but never discuss this openly with him. He soon realizes that they are all lying, and that he shall soon die. The "therapeutic privilege" that the doctors and family claim for themselves in this novel excavates a gulf of incommunicability between the protagonist and all others. He lives his last days while feeling betrayed by his own family and sinking in an "abyss" of loneliness, as he himself describes. The novel portrays excellently the psychology of this terminally ill patient. He does not want hope, but compassion. The novel can be useful to discuss in depth various ethical issues relating to breaking bad news and therapeutic privilege. Giving hope is part of good care, but the novel shows that a fine balance needs to be drawn between encouraging patients and ensuring they receive the compassion they need.

Legal issues of consent and confidentiality are also discussed in the e-lecture. Reading material, in the form of lecture notes and power point presentations, is uploaded in the VLE for the students, together with questions for discussion. The 
Table 2. Students' Entries

Student on Q1. I do agree with [Hume]. However if one were [to] apply this discretely to research then one may suggest that all research and its application can take place regardless of ethical or moral objections. However Hume later states:

"And how does it appear that the Almighty is displeased with those actions that disturb society? By the principles which he has implanted in human nature, and which inspire us with a sentiment of remorse if we ourselves have been guilty of such actions, and with that of blame and disapprobation if we ever observe them in others."

This suggests humans are capable of making moral and ethical judgments based on our own inherent thoughts and emotions which have been handed down to us by God. The counter argument to this is that morals and emotions are not inert and are subject to change: in the past actions have taken place which are now perceived to be crimes.

Student on Q3. I am not sure of bravery and cowardice, but one memory sticks in my mind, which this question reminded me of: I will not forget a conversation I heard on the bus once, between two young girls. One of them had been to London and was telling her friend how the tubes had been delayed, as someone had jumped onto the tracks to end their life. They discussed, rather ignorantly in my opinion, how selfish this person had been to delay everyone's schedules.

Yes, this person's suicide affected the "universe" around him or her. But to fellow travellers, it probably caused little more than a mild inconvenience. I thought the girls' comments rather ironic, as they were being selfish in their unforgiving views of this person. However, we can look at how else this act may be considered to be selfish: it is selfish towards the loved ones that they leave behind: "Was it because I said this?" "Was it because I did that?" "Was it because I didn't do this?" "If I say this to ' $X^{\prime}$, will they kill themseleves too?" It is selfish to the individual who finds them. Selfish towards the person who has to physically clear the scene, which as often in the case of young men who commit suicide, extremely violent. I am sure we have all met patients during our psychiatric placements who have a history of suicide in their family, which has scarred them deeply.

Although I do believe it is selfish to end one's life, I do not believe that anyone in such a desperate situation has the capacity to judge what is selfish and what is not. I do not believe that it is brave, or cowardly. I believe that to take such drastic measures, one must feel so desperately unhappy that one can think of nothing else but how to end this haunting feeling.

I do not know if it is wrong to end your life. For where it may not be wrong towards yourself, it may be wrong towards others. And where one person ends their own misery, perhaps this is where and why, another's begins.

Student: Hume's argument that "failing to do good is more acceptable than doing harm" has started to make my head spin.

Hopefully it is not too glib to cite the Frank Capra film It's a Wonderful Life as really providing a powerful argument that withdrawing from society can be as bad as doing harm. In this film we see the unintended consequences of the suicide of a bankrupt businessman (Jimmy Stewart). Stewart is guided by an angel to view the world as if he had not existed. It is not so much the direct harm he causes, rather it is the good that he has done in his life which positively influences the lives of others. It is a fantasy but is a film that really connects, possibly because it highlights the fact that, no matter how worthless or wretched a life may be, individuals have the ability to enrich other lives both by intentional acts and just as a result of their very presence.

If you have not seen it, I suggest you watch it-have some hankies available!

RE: Hadn't seen this film before but glad you recommended it!

I think it is often very easy for one to underestimate the impact an individual has in society. In our everyday lives, by the things we do and the things we say we are unknowingly influencing the lives of all those we interact with. It reinforces the age-old advice that "you should think before you act,"- as you never know what the repercussions of your words or actions are going to be! 
RE: You have made me feel quite nostalgic-I love this film!

I think you make a very good point. And even though this is a rather fantastical film, it's a point that can be made well if you look at parenting:

One only has to watch daytime TV (Jeremy Kyle anyone?) to see the effect on one's life of having an absent parent. I was watching a documentary on foster care the other day, and one of the foster parents was saying how the children she cared for over the years would always worship their parents, no matter how much harm they had done, or how little love they had shown towards them.

Again, looking within the media spotlight, take someone such as Kerry Katona. For those of you who are not avid "Heat" readers, Kerry Katona was largely brought up in care, and has since tried very hard to forge a relationship with her mother, who has gone on to sell various stories about her daughter. Kerry suffers from bipolar disorder. She allegedly uses recreational drugs, and is in what seems to be a controlling and rather disturbing marriage. However, Kerry still strives to have a relationship with her mother. Her upbringing has clearly had a massive effect on her life, and furthermore on the life of her children.

Although it may seem a little off the point (and highlight my penchant for celebrity gossip and daytime TV), I think this highlights Mark's point well. Someone's absence, or failing to do good, can have a phenomenal impact on society.

Student on Q1: As has been discussed, the concept of a human action being termed unnatural may well be a fallacy. If this is true, the implications with respect to medical interventions such as genetic enhancement may be that nature can no longer be used as an argument for or against an intervention. Nature, however, is not the only issue to consider. On the contrary, removing this debate may allow for a more thorough discussion of the remaining issues. At this point I'll recommend the film Gattaca. While it's not the greatest film of all time it does tackle some issues posed by a theoretical projection of what gene therapy could become. Especially interesting are the societal effects on an individual who has been born naturally into a world of genetically enhanced superhumans. So the question of nature can amount to irrelevance and be replaced with a question of positive and negative implications of an action on a case-by-case basis. I would agree that being a human is special, but only to the extent that having an individually unique place in the world is special. The ability to propel objects out of the earth's gravitational pull is certainly special, but then again so is being able to fly using only the wings you were born with or being massive enough to contain all but the most powerfully propelled objects within your gravitational pull.

real case in this session is Piergiorgio Welby. ${ }^{17}$ Welby was affected by muscular dystrophy. He accepted a tracheotomy. Later, when it was clear that he was going to suffer death by suffocation, he requested removal of life support and appropriate sedation. The Italian law was not clear as to whether such procedures could be equated to euthanasia and whether it was therefore lawful. The anesthesiologist who agreed to carry out the procedure was accused of manslaughter and later found not guilty. Reading material is provided that explores the ethical issues relating to the right to end our life and the terminological and ethical differentiation between withdrawing and withholding medical treatment.

\section{Session 3: Brief Overview}

The final session is "Medicine and Theater." The theater play Wit, by Margaret Edson, is the main theme. The students are required to read the play or watch the film inspired by the play. In Wit, Professor Bearing is diagnosed with ovarian cancer. She is persuaded to enroll in a therapeutic research program. When it is clear that she will not recover, nurse Susie suggests that she think about signing 
a do-not-resuscitate order. In spite of this, when her heart stops beating, the junior and ambitious researcher Jason calls for the resuscitating team. "She is research," he shouts, as he refuses to let her go.

In the e-lecture, ethical and legal issues relating to participation in medical research by people affected by terminal illnesses are identified. The right to remain ignorant and the right not to participate in medical research are questioned, and the ethics of do-not-resuscitate orders is also discussed, in particular in cases of subjects who could be used in medical research. Questions for discussion are uploaded. Both Sessions 2 and 3 end with 1-week online discussion.

\section{E-learning: Challenges and Solutions for Medical Education}

Teaching medical ethics to medical students is challenging in many ways. One major difficulty is the students' numbers and limited teaching resources. In Manchester, we have around 2,000 students across the 5 years. During Year 5, the students are in placement. Some are undertaking periods of training abroad. The traditional face-to-face teaching in a lecture theater, therefore, often cannot be utilized. If we want to continue to deliver ethics to the students across the 5 years, it is necessary to explore alternative solutions, using new technologies.

E-learning is a growing component in medical education. Examples of e-learning in medical education include virtual clinics, tele-medicine, problem-based learning, supporting group projects, e-portfolios, ${ }^{18}$ digital storytelling, ${ }^{19}$ and many others. ${ }^{20}$

According to the International Association for Medical Education (AMEE) guidelines, face-to-face interaction is the best form of teaching. ${ }^{21}$ Yet, new technologies can offer valuable solutions and have important advantages over the traditional lecturing style. E-learning needs to be carefully planned and, possibly, integrated with other teaching methods. ${ }^{22}$ In the remaining sections, therefore, I discuss the advantages and disadvantages of e-learning and how this can be integrated in a wider curriculum.

\section{Advantages of E-learning Modules}

Because in Year 1 to 4 we already have a rich medical ethics and law curriculum in place, the best year to deliver the MHM is Year 5. For us in Manchester, an elearning module is probably the only way in which we can reach students at Year 5. So, regardless of any other consideration, we have a net gain (unless of course what we teach is so bad that the students are better off not to receive it).

However, there are more general advantages in e-learning:

- E-learning modules are cost-effective.

- "Web/DVD e-learning . . . allows for the rapid and relatively inexpensive updating of material." 23

- An e-learning module is an effective and practical way to allow greater numbers of students (including those on electives abroad) to access the resource. $^{24}$

- It allows students large discretion as to how to organize and prioritize their workload. This also means that, the students' being able to work and participate in discussions at their own pace, their attention is generally greater and their input, overall, is of greater quality. 
- E-learning modules allow the students to rewatch the material, pause the electure, and return to it at more convenient times. This decreases the risk of misunderstandings or loss of information, which are more likely to occur in traditional lecture theaters.

- "Studies demonstrate significant increases in final examination marks for students accessing material as virtual lectures compared with merely viewing web pages."25

- Online forums are thought to be more apt than face-to-face discussion to practice the "intellectual and communicative skills required for discussing ethical issues."26

There are, however, a number of disadvantages, which are important to identify in order to frame strategies to prevent and resolve these.

\section{Disadvantages of E-learning in Ethics and Law}

The main disadvantage of the e-learning system is that the human interaction among students and students and teachers is missing. This can be frustrating for the educator and somehow affect the learning experience of the students. Thakore and McMahon point out that the absence of face-to-face interaction can negatively affect the students' ability to relate successfully with their patients in the long term. This ability is obviously crucial for what concerns ethical action. They argue that "the clinical encounter lies at the heart of medical training. . . . It is the ability to relate to patients and apply their knowledge during clinical encounters that will be the ultimate mark of their success as doctors." 27

The students could also benefit in other ways from direct interaction and confrontation with their colleagues and teachers. During a live discussion, for example, the students need to master their ethics beliefs and their reactions in a way that is not required online and that is more in line with their future experience in clinical practice. An important benefit of direct face-to-face debate with people who hold different views is thus lacking in the online forum.

These disadvantages can partly be counteracted by ensuring that e-learning is incorporated in a broader program, which should also include face-to-face learning experiences in ethics and law. Available research on the effectiveness of e-learning suggests that this should not be the sole method of learning for the students. $^{28}$

In addition to this, interactive elements and activities that require feedback should also be included in any e-module. Price Kerfoot et al. report that in their study "students perceived that interactive web-based modules generate greater learning than a non-interactive mode of delivery." 29

Another important disadvantage of e-learning is that preparation is very timeconsuming. Once ready, the module can, of course, run again. However, legal provisions change in many areas of healthcare law. The same can be said of ethics, especially as the traditional and important themes of consent, confidentiality, genetics, the end of life, and the others that form a part of the core curriculum are always subject to scholarly scrutiny. For example, in 2009 the GMC published amended guidelines on confidentiality. ${ }^{30}$ Designing, preparing, and updating online material takes significantly greater time and acquisition of new skills on the part of the tutor than is necessary for standard teaching. The 
educator has to learn how to use various types of software needed to design and deliver the course. Whereas, thus, the educators' numbers can be reduced, the time required from each of them probably is more than for face-to-face teaching.

Another disadvantage of e-learning is that, if it runs for large student numbers, it will be necessary to hire extra tutors for the discussion forums. Thus, whereas there will probably still be a net gain in terms of utilized resources, a team of tutors will still be necessary.

\section{Discussion of the Online Forum}

My initial impression of the online forum was that the number of questions and comments was greater in comparison with traditional face-to-face teaching. Moreover, the entries seemed to be well thought out and carefully articulated (see Tables 1 and 2). My impression is validated by a number of studies on online forums in medical education. Buelens et al. report "higher participation rates and more developed comments in online discussions compared with face-to-face debate." ${ }^{\prime 31}$

This might depend on a number of factors. The students have more time to reflect on what is said and on their reading and to form ideas and questions to share. Moreover, expressing opinions "behind the screen" might enable the shier and more introverted students (those who would not speak aloud in a lecture theater) to offer their input.

There are, however, downsides to online forums, which have been identified in the literature. Students might fail to participate, or they may write about irrelevant issues. $^{32}$ To minimize these risks, researchers have stressed the importance of composing a list of etiquette (or "netiquette") and didactic recommendations, aimed at improving the effectiveness of electronic interactions among the students and with the tutors. These include the following recommendations: to pay attention "to spelling, grammar, tone, and style and to refrain from posting offensive contributions"; "to have a second look at the linguistic and formal correctness of their contributions before posting it"; to realize that "ethics is not just a matter of personal opinion"; to "build strong reasoning, to bring in good arguments and to stress the (causal) relationships between these elements"; to "first read the contributions of others, to ask for clarifications or to respond to the writings of others, thereby starting by summarizing or paraphrasing the gist of the initial position." ${ }^{\prime \prime 3}$

Discussion forums that enclose both etiquette and didactic guidelines prove to be more effective, containing better articulated entries and overall better argumentation of the given topics.

\section{Conclusions}

Medical humanities can and should be central to medical education. Baños writes: "Literature and films provide new ways of introducing medical students to the reality of their future activities [and enable them to] better understand their future profession." ${ }^{\prime 34}$ Not only literature and films but artworks and a discourse on the history of medicine and its relationship with arts, architecture, law, philosophy, and sociology can all enhance the future doctors' capacity to appreciate ethical dilemmas that they will encounter in clinical practice and refine their capacity to deal sensitively with these dilemmas. 


\section{Simona Giordano}

In response to the GMC and BMA call for integration of humanities in the medical curriculum, the Manchester Medical School has accepted the offer to include a MHM in the undergraduate medical curriculum. This paper has provided a review of the MHM, launched in 2008-2009 as a pilot study, with 30 students voluntarily enrolled.

The experience has been extremely rewarding, and positive feedback has been received from both medical colleagues and the students. The lively discussions in the online forums were additional evidence of how the students found the module valuable.

I have provided an account of the aims and a brief outlook of the content of the module. In doing so, I hope to have inspired other medical educators with practical ideas to be used in medical ethics and law teaching at all levels of medical education. My program does not pretend to be exhaustive: much more could be offered, and many different subjects, films, novels, works of arts, and philosophy could be covered. I only offer the students my own interpretation of medical humanities and of how various works from other disciplines can be useful to enhance our ability to deal with human persons in the clinical work with refined sensitivity.

I have discussed here the e-learning method as applied to this MHM. The pros and cons of e-learning versus standard face-to-face teaching have been discussed. E-learning has pitfalls, like any other learning method. It will suit some students better than others, and some might not accept it as readily as others. However, elearning has great advantages, especially if provided in concomitance with other learning experiences. It allows larger numbers of students to access the resources we can offer and is a cost-effective way of reaching students who might be unable to join the lecture theater. These, and the other discussed above, are major reasons to consider it as a valuable learning method that can easily be incorporated at all levels of medical education.

\section{Notes}

1. General Medical Council, Tomorrow's Doctors, 2003 edition, point 4.1, available at http://www. gmc-uk.org/education/undergraduate/undergraduate_policy/tomorrows_doctors.asp (last accessed 26 May 2010). A review was published in September 2009.

2. Evans M, Greaves D. Exploring the medical humanities. British Medical Journal 1999;319:1216.

3. Institute of Medical Ethics, Conference on Supporting the Integrated Teaching, Learning and Assessment of Medical Ethics and Law in UK Medical Schools, BMA House, 25 Jan 2008; available at www.instituteofmedicalethics.org/.../IMEConferenceReport25March2008.pdf (last accessed 26 May 2010).

4. American Society for Bioethics and Humanities, ASBH Task Force on Ethics and Humanities Education in Undergraduate Medical Programs; available at http:/ /www.asbh.org/publications / pdfs/lcmereport.pdf (last accessed 26 May 2010).

5. Weng H-C, Chen H-C, Chen H-J, Lu K, Hung S-Y. Doctors' emotional intelligence and the patientdoctor relationship. Medical Education 2008;42(7):703-11; Sandars J. The use of reflection in medical education: AMEE Guide No. 44. Medical Teacher 2009;31(8):685-95.

6. Hope T. Ethics and law for medical students: The core curriculum. Journal of Medical Ethics 1998;24:147-8.

7. One illustration is available at http://www.gothicnetwork.org/files/images/Michelangelo_ Cappella\%20Sistina.display.jpg

8. One illustration of his pieces is available at http://blogs.nyu.edu/blogs/ah785/allisonhop/ 29198-large.jpg 


\section{Medical Humanities E-Module}

9. A similar exhibition with a focus on radiography was held in London in 2009; see The Londonist Review: The arts of medicine at the BIR; available at http://londonist.com/2009/03/ review_the_art_of_medicine_at_the_b.php (last accessed 26 May 2010).

10. One image is available at http://theinspirationroom.com/daily/print/2007/4/pietamichelangelo.jpg. A wonderful detail can be found at http://www.artknowledgenews.com/ files2008/pieta500.jpg (last accessed 26 May 2010). The photo was taken by Aurelio Amendola and published in Michelangelo, La Dotta Mano, FMR, Collezione Privata; 2008.

11. Available at http://www.medecine-des-arts.com/local/cache-vignettes/L97xH127/bac15bis6d254.jpg (last accessed 26 May 2010).

12. See, for example, http://images.pennnet.com/articles/bow/cap/cap_278074.jpg (last accessed 26 May 2010).

13. One photo is available at http://www.freewebs.com/astobbe/city-of-arts-science02.jpg (last accessed 26 May 2010).

14. See, for example, http://science.kukuchew.com/wp-content/uploads/2008/06/leonardo-davinci-heart.gif (last accessed 26 May 2010).

15. International Arts-Medicine Association; available at http://www.iamaonline.org (last accessed 5 May 2010).

16. A brief account can be found on Wikipedia at http:/ / en.wikipedia.org/wiki/Eluana_Englaro (last accessed 26 May 2010).

17. Wikipedia at http://en.wikipedia.org/wiki/Piergiorgio_Welby (last accessed 26 May 2010).

18. Murray C, Sandars J. AMEE Guide Supplements: E-learning in medical education: Guide supplement 32.2-Practical application. Medical Teacher 2009;31:364-5.

19. Pyne N. E-Learning in medical education: Guide supplement 32.3-Practical application. Medical Teacher 2009;31:366-7.

20. Bilham T. AMEE Guide Supplements: E-learning in medical education: Guide supplement 32.5-Viewpoint. Medical Teacher 2009;31:449-51 at p. 449. An interesting description of the virtual learning environment can be found in Senaka R, Deepika F, Nadun R, Suranja G. AMEE guide supplements: E-learning in medical education: Guide supplement 32.6-Practical application. Medical Teacher 2009;31:452-3. See also Fuller R, Coulby C, Homer-Vanniasinkam S, Hennessy S, Davis N. E-learning in medical education: Guide supplement 32.4-Practical application. Medical Teacher 2009;31:368-9.

21. Sandars J. E-learning in medical education: Guide Supplement 32.1-Viewpoint. Medical Teacher 2009;31:362-3, citing Llaway R, Masters K. E-learning in medical education: AMEE Guide No. 32. Medical Teacher 2008;30:455-74.

22. See note 15, Sandars 2009:362-3.

23. Thakore H, McMahon T. Virtually there: E-learning in medical education. The Clinical Teacher 2006;3:225-8 at p. 226

24. See note 17, Thakore, McMahon 2006:226.

25. See note 17, Thakore, McMahon 2006:226. See also Evans C, Gibbons N, Shah K, Griffin D. Virtual learning in the biological sciences: Pitfalls of simply 'putting notes on the web.' Computers $\mathcal{E}$ Education 2004;43:49-61.

26. Buelens H, Totté N, Deketelaere A, Dierickx K. Electronic discussion forums in medical ethics education: The impact of didactic guidelines and netiquette. Medical Education 2007:41:711-7 at p. 711. See also Edwards K, Wilkins MD, Baernstein A, Braddock CH. Bringing ethics education to the clinical years. Ward ethics sessions at the University of Washington. Academic Medicine 2006;81:626-31. Ellenchild Pinch WJ, Graves JK. Using web-based discussion as a teaching strategy: Bioethics as an exemplar. Journal of Advanced Nursing 2000;32:704-12.

27. See note 17, Thakore, McMahon 2006:227.

28. See note 14, Bilham 2009:449.

29. Price Kerfoot B, Conlin RP, McMahon TG. Comparison of delivery modes for online medical education. Medical Education 2006;40(11):1137-8 at p. 1137.

30. GMC. Confidentiality. 2009; Available at http://www.gmc-uk.org/static/documents/content/ Confidentiality_core_2009.pdf (last accessed 26 May 2010).

31. See note 26, Buelens et al. 2007:711.

32. See note 26, Buelens et al. 2007:711.

33. See note 26, Buelens et al. 2007:713.

34. Baños Josep E. How literature and popular movies can help in medical education: Applications for teaching the doctor-patient relationship. Medical Education 2007;41(9):918. 